\title{
Correction to: Energy-Efficiency-Based Power Allocation Scheme in Multi-user Single-DF-Relay Cognitive Networks
}

\author{
Xianru Liu ${ }^{1}$ (D) $\cdot$ Wenhao Du ${ }^{1}$
}

Published online: 6 July 2020

(c) Springer Science+Business Media, LLC, part of Springer Nature 2020

\section{Correction to: Wireless Personal Communications https://doi.org/10.1007/s11277-020-07455-3}

There was a typo in the second author's name in the initial online publication. The original article has been corrected.

Publisher's Note Springer Nature remains neutral with regard to jurisdictional claims in published maps and institutional affiliations.

The original article can be found online at https://doi.org/10.1007/s11277-020-07455-3.

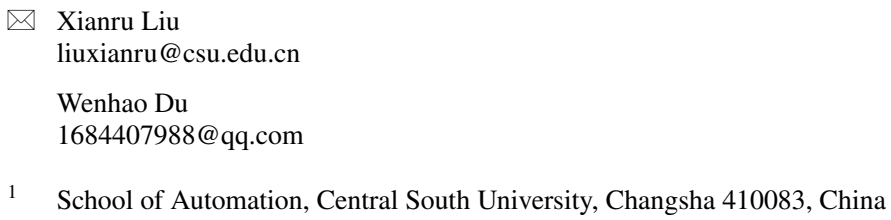

